University of Texas Rio Grande Valley

ScholarWorks @ UTRGV

8-19-2020

\title{
Inter-organizational systems use and supply chain performance: Mediating role of supply chain management capabilities
}

\author{
David Asamoah \\ B. Agyei-Owusu \\ Francis K. Andoh-Baidoo \\ The University of Texas Rio Grande Valley \\ Emmanuel Wusuhon Yanibo Ayaburi \\ The University of Texas Rio Grande Valley
}

Follow this and additional works at: https://scholarworks.utrgv.edu/is_fac

Part of the Operations and Supply Chain Management Commons

\section{Recommended Citation}

Asamoah, D., B. Agyei-Owusu, F. K. Andoh-Baidoo, and E. Ayaburi. 2020. "Inter-Organizational Systems Use and Supply Chain Performance: Mediating Role of Supply Chain Management Capabilities." International Journal of Information Management, August, 102195. https://doi.org/10.1016/ j.ijinfomgt.2020.102195.

This Article is brought to you for free and open access by the Robert C. Vackar College of Business \& Entrepreneurship at ScholarWorks @ UTRGV. It has been accepted for inclusion in Information Systems Faculty Publications and Presentations by an authorized administrator of ScholarWorks @ UTRGV. For more information, please contact justin.white@utrgv.edu,william.flores01@utrgv.edu. 


\title{
Inter-organizational systems use and supply chain performance: mediating role of supply chain management capabilities
}

\begin{abstract}
Inter-organizational Systems (IOS) are network-enabled information systems that extend boundaries of an organization. There is a growing interest among researchers and practitioners to understand how the use of IOS enhances firm performance. In this study, we examine how IOS use impacts an organization's supply chain management (SCM) capabilities and supply chain performance. Drawing on the resource-based view theory, we examine two mechanisms that are essential for enhanced supply chain performance: (a) efficient IOS external utilization regarding its networked partners and (b) the maximization of IOS organizational management capabilities in supply chain management. Using data from 193 respondents from various manufacturers and distributors of fast-moving consumer goods, we confirm all the hypotheses posited in the research model. The results demonstrate the dual effect of IOS use in improving operational supply chain performance, SCM capabilities, and the mediating role of SCM capabilities. We discuss contributions of the study to research and practice.
\end{abstract}

Keywords: Inter-organizational systems use, supply chain management capabilities, supply chain performance, resource-based view

\section{Introduction}

Inter-organizational systems (IOS), network-enabled enterprise systems, extend beyond the borders of an organization, enabling external entities such as supply chain partners to share business information in real time and to collaborate more effectively (Bakos, 1991; Chatterjee \& Ravichandran, 2004; Hartono et al., 2010). Firms have deployed diverse IOS including electronic data interchange, vendor managed inventory, and collaborative planning, forecasting and replenishment for real time communication and intelligent decision making with supply chain partners. Inter-organizational systems facilitate effective management of activities in a coordinated and integrated fashion to competitive advantage. 
The resource-based view (RBV) theory postulates that a firm gains competitive advantage when it controls and effectively combines resources that are rare, valuable, heterogeneous and inimitable (Barney, 1991; Peteraf \& Barney, 2003). IOS enables an organization to augment its internal resources and capabilities with external resources available to the partners for the mutual benefits of the members of the supply chain network. Previous IOS research suggests that IOS use results in significant benefits to the entire supply chain (Asamoah et al., 2019; Hartono et al., 2010). However, there are calls for opening the supply chain Blackbox and further investigating the mechanisms through which IOS use enhances supply chain performance (Agbenyo et al., 2018; Aydiner et al., 2019; Yu et al., 2018). The current study focuses on 1) external utilization of IOS in SCM and 2) IOS organizational management capabilities in the context of SCM. Insights from the examination of the interplay between IOS use and SCM capabilities in enhancing supply chain performance enriches management's understanding of operational dynamics of IOS in the organization. In this study, we explore intricate interplay between IOS use, SCM capabilities and supply chain performance. The thesis of this study is that, IOS use does not only play a singular role in enhancing supply chain performance. Thus, the study research questions are: (1) How does IOS external utilization capabilities affect firms' supply chain performance? and (2) How do SCM capabilities influence supply chain performance in the presence of IOS use?

This study draws on RBV to advance a model that investigates the research questions. To empirically validate our model, we asked top management members of large manufacturing firms and distributors of fast-moving consumer goods (FMCG) to answer survey questions based on key constructs of our model. The results of the study reveal the need to concurrently manage and leverage SCM capabilities in using IOS for greater supply chain performance. The study makes theoretical contributions to SCM and information systems literature. First, the study proposes and empirically tests the effect of information technology artefact that extends firm boundary in the context of supply chain. Second, the study demonstrates the intricate interplay between IOS use, SCM capabilities and firm performance, by examining how IOS use enhances supply chain performance, directly and indirectly through SCM capabilities. For practice, results of the study provide insights for managers by suggesting that, the full benefits of IOS use can be realized by investing in the development of the needed SCM capabilities in the firm. 
The rest of the paper is structured as follows: a discussion of the theoretical background is presented next, followed by a discussion of the theoretical model and research hypotheses. The research methodology is then presented, leading to the presentation and discussion of the results of the study. The implications of the study, limitations of the study, and directions for future research are then presented in the concluding parts of the paper.

\section{Literature review}

\subsection{Supply chain performance}

Prior studies have investigated various supply chain performance outcomes from IOS implementation in organizations. For instance, Hartono et al. (2010) studied the antecedents and outcome of IOS information quality. Quality information from IOS enhances supply chain performance through informed and timely decision-making (Lee et al., 2014). IOS-enabled virtual integration and good relational governance significantly impacts information visibility, leading to enhanced supply chain flexibility (Wang \& Wei, 2007). Effective IOS governance mechanisms and IT ambidexterity influence the performance of the firm and its partners (Chi et al., 2017). Yet, other studies suggest the need for firms to develop collaborative culture to maximize the benefits of IOS in supply chain (Zhang \& Cao, 2018). Table 1 presents key relevant empirical literature on IOS and performance. The current study focuses on firm's IOS utilization practices. Utilization of insights from the deployment of IOS depends on the development of appropriate capabilities especially in the supply chain context. This study attempts to explore the intricate interplay between IOS use, SCM capability and supply chain performance.

\section{Table 1.}

Key Literature on IOS and Performance

\begin{tabular}{|c|c|c|c|c|}
\hline Author(s) & Problem & Theory & Outcome & Findings \\
\hline $\begin{array}{l}\text { Chi et al. } \\
\text { (2017) }\end{array}$ & $\begin{array}{l}\text { The study examined the } \\
\text { moderating effect of IT } \\
\text { Ambidexterity on the } \\
\text { relationship between } \\
\text { inter-firm IT } \\
\text { governance strategy } \\
\text { and relational } \\
\text { performance. }\end{array}$ & RBV theory & $\begin{array}{l}\text { Relational } \\
\text { performance }\end{array}$ & $\begin{array}{l}\text { Both inter-firm IT governance } \\
\text { strategies can help increase } \\
\text { relational performance, and IT } \\
\text { ambidexterity can also } \\
\text { influence the choice of } \\
\text { governance strategies of focal } \\
\text { firms. }\end{array}$ \\
\hline
\end{tabular}




\begin{tabular}{|c|c|c|c|c|}
\hline $\begin{array}{l}\text { Hartono et } \\
\text { al. (2010) }\end{array}$ & $\begin{array}{l}\text { The study examined the } \\
\text { antecedents and } \\
\text { outcomes of IOS } \\
\text { information quality. } \\
\text { Antecedents include IT } \\
\text { infrastructure capability } \\
\text { and top management } \\
\text { support. The outcomes } \\
\text { include operational } \\
\text { supply chain } \\
\text { performance and } \\
\text { overall firm } \\
\text { performance. }\end{array}$ & & $\begin{array}{l}\text { Information } \\
\text { sharing }\end{array}$ & $\begin{array}{l}\text { The antecedents influence IOS } \\
\text { information quality, which } \\
\text { subsequently influences the } \\
\text { outcomes. }\end{array}$ \\
\hline $\begin{array}{l}\text { Lee et al. } \\
(2014)\end{array}$ & $\begin{array}{l}\text { The study examined the } \\
\text { antecedents of IOS } \\
\text { visibility and how IOS } \\
\text { visibility impacted } \\
\text { supply chain } \\
\text { performance. }\end{array}$ & $\begin{array}{l}\text { Resource } \\
\text { dependence } \\
\text { theory and } \\
\text { relational } \\
\text { view theory }\end{array}$ & $\begin{array}{l}\text { Supply chain } \\
\text { performance }\end{array}$ & $\begin{array}{l}\text { IOS visibility significantly } \\
\text { enhances supply chain } \\
\text { performance. }\end{array}$ \\
\hline $\begin{array}{l}\text { Wang \& } \\
\text { Wei } \\
(2007)\end{array}$ & $\begin{array}{l}\text { The study examined the } \\
\text { effect of relational } \\
\text { governance and IOS } \\
\text { enabled virtual } \\
\text { integration on } \\
\text { information visibility } \\
\text { and supply chain } \\
\text { offering flexibility. }\end{array}$ & $\begin{array}{l}\text { Transaction } \\
\text { cost } \\
\text { economics } \\
\text { and RBV } \\
\text { theory }\end{array}$ & $\begin{array}{l}\text { Supply chain } \\
\text { offering } \\
\text { flexibility }\end{array}$ & $\begin{array}{l}\text { Both relational governance and } \\
\text { virtual integration were } \\
\text { important influencers of } \\
\text { information visibility and } \\
\text { supply chain offering } \\
\text { flexibility. }\end{array}$ \\
\hline $\begin{array}{l}\text { Zhang and } \\
\text { Cao } \\
(2018)\end{array}$ & $\begin{array}{l}\text { The study examined the } \\
\text { effect of collaborative } \\
\text { culture on IOS use and } \\
\text { supply chain } \\
\text { collaboration. }\end{array}$ & $\begin{array}{l}\text { Hofstede's } \\
\text { Theory }\end{array}$ & $\begin{array}{l}\text { Supply chain } \\
\text { collaboration }\end{array}$ & $\begin{array}{l}\text { Collaborative culture enhances } \\
\text { supply chain collaboration } \\
\text { directly and indirectly by } \\
\text { facilitating IOS use, which in } \\
\text { turn improves supply chain } \\
\text { collaboration. IOS use also } \\
\text { partially mediates the } \\
\text { relationship between } \\
\text { collaborative culture and supply } \\
\text { chain collaboration. }\end{array}$ \\
\hline
\end{tabular}

\subsection{Supply chain capabilities}

Firms realize benefits from IOS when they develop the needed capabilities to maximize the use of the features of IOS. Capabilities refer to the ability of an organization to identify, utilize, and assimilate both internal and external resources/information to facilitate its entire activities (Wu et 
al., 2006). Table 2 shows key literature that employ RBV to highlight the need to develop the capacity to utilize internal/external resources for firm performance. Information systems capabilities play significant role in decision-making, business-process performance and firmperformance (Aydiner et al., 2019). An IOS-enabled data-driven supply chain has a significant positive influence on supply chain capabilities. Firms that have developed coordination and responsiveness capabilities, dimensions of supply capabilities, demonstrated significant financial performance (Liao \& Kuo, 2014; Yu et al., 2018). Despite the insights from these prior research, further investigation of cross-boundary spanning IT artefacts (e.g. IOS) enhancing processes and routine, key capabilities, would provide additional understanding for research and practice. The review of the literature revealed that need to examine the mediating role of SCM capabilities in the relationship between IOS use and supply chain performance. Thus, we also seek to examine the interaction between IOS use and SCM capabilities, and the subsequent effect of SCM capabilities in driving supply chain performance.

\section{Table 2.}

Key Literature on SCM Capabilities and Performance

\begin{tabular}{|c|c|c|c|c|}
\hline Author(s) & Problem & Theory & Context & Findings \\
\hline $\begin{array}{l}\text { Aydiner et } \\
\text { al. (2019) }\end{array}$ & $\begin{array}{l}\text { This study examines the } \\
\text { interrelationships } \\
\text { between information } \\
\text { systems-related } \\
\text { capabilities and their } \\
\text { effects on firm } \\
\text { performance. }\end{array}$ & RBV & $\begin{array}{l}\text { Business process } \\
\text { performance }\end{array}$ & $\begin{array}{l}\text { There is mediation effect } \\
\text { between infrastructure } \\
\text { related IS capabilities and } \\
\text { firm performance. }\end{array}$ \\
\hline $\begin{array}{l}\text { Yu et al., } \\
(2018)\end{array}$ & $\begin{array}{l}\text { The study examined how } \\
\text { big data-driven supply } \\
\text { chains affect supply chain } \\
\text { capabilities, followed by } \\
\text { the exploration of the } \\
\text { effect of data-driven } \\
\text { supply chain capabilities } \\
\text { on financial performance. }\end{array}$ & RBV & $\begin{array}{l}\text { Financial } \\
\text { Performance }\end{array}$ & $\begin{array}{l}\text { A data-driven supply } \\
\text { chain has a significant } \\
\text { positive influence on } \\
\text { supply chain capabilities. } \\
\text { Coordination and supply } \\
\text { chain responsiveness are } \\
\text { positively and } \\
\text { significantly related to } \\
\text { financial performance. }\end{array}$ \\
\hline $\begin{array}{l}\text { Liao and } \\
\text { Kuo } \\
(2014)\end{array}$ & $\begin{array}{l}\text { The study examined } \\
\text { whether collaborative } \\
\text { supply chain value } \\
\text { innovation, and supply } \\
\text { chain capability improves } \\
\text { firm performance. }\end{array}$ & RBV & $\begin{array}{ll}\text { Supply } & \text { Chain } \\
\text { Performance } & \end{array}$ & $\begin{array}{l}\text { Collaborative } r \text { supply } \\
\text { chain value innovation } \\
\text { improves supply chain } \\
\text { capability and firm } \\
\text { performance. }\end{array}$ \\
\hline
\end{tabular}




\section{Theoretical background and hypotheses development}

The current study draws on the RBV to explore the relationships between IOS use, SCM capabilities and supply chain performance. RBV emphasizes the maximization of internal resources and opportunities to organizations to create unique and non-transferable assets. The importance of internal and external resources in creating and sustaining competitive advantage has been highlighted in business-to-business research (Danneels, 2008; Helfat \& Peteraf, 2003; Möller \& Svahn, 2006; Rajaguru \& Matanda, 2013; Teece et al., 1997). Resources refer to the assets or factors of production a firm owns or controls (Amit \& Schoemaker, 1993), and may be tangible, intangible, or human (Cepeda \& Vera, 2007). These resources may reside within or outside the organization. According to the RBV, firms can achieve sustainable competitive advantage when they control resources which are rare, valuable, heterogeneous and inimitable (Barney, 1991; Peteraf \& Barney, 2003).

Inter-organization systems are organizational resources. However, merely owning and controlling valuable resources are not enough to create and sustain competitive advantage over time. Firms need to combine and deploy these resources in unique ways to gain competitive advantage. Management needs knowledge and skills to deploy these resources. Organizational capabilities or skills builds on the interaction of resources. Organizational capabilities is defined as "information-based tangible or intangible processes that are firm specific and are developed over time through complex interactions among the firm's resources" (Amit and Schoemaker, 1993, p. 35). Organizational capabilities cover "bundle of aptitudes, skills and technologies that a firm performs better than its competitors, that is difficult to imitate and provides an advantage in the marketplace" (Coates \& McDermott, 2002, p. 436). Thus, capabilities deal with a firm's capacity to deploy resources and achieve specific goals. This study identifies four intra and interfirm capabilities that are essential in deploying IOS in the SCM context to achieve superior supply chain performance. These are supply chain information exchange, supply chain integration, supply chain coordination and supply chain responsiveness.

Based on the RBV theory, we postulate that using IOS can directly enhance the supply chain performance of firms, and indirectly enhance supply chain performance through enhanced SCM capabilities by creating tangible and intangible unique assets. The assets create competitive advantage in supply chain performance and lead to the development of SCM capabilities. The 
assets create competitive advantage for the firm through supply chain performance. In the proposed research model, we argue that IOS use for communication and intelligence serves as a resource that can be leveraged for higher supply chain performance and to create capabilities for supply chain information exchange, supply chain integration, supply chain coordination and supply chain responsiveness in several contexts. Developing and leveraging these capabilities obtained from the use of IOS can further help firms achieve greater supply chain performance. IOS use in this study refers to the extent to which firms have adopted and are using IOS in their operations for the accumulation and dissemination of information and development of business insights (Zhang \& Cao, 2018). Exploration of IOS usage patterns can lead to diverse outcomes, even when the context of use and underlying technologies are similar (Subramani, 2004). Building on this, Zhang and Cao (2018) proposed three patterns of IOS use, namely for communication, integration and intelligence. This study adapted this conceptualization, focusing on IOS use for communication and intelligence. IOS use for communication refers to the extent to which IOS is used to facilitate and coordinate flow of information between supply chain partners. IOS technologies and applications including message services, channel management, communications network, and communication standards and protocols enable inter-firm communication (Zhang \& Cao, 2018). IOS use for intelligence refers to the extent to which IOS is used to enhance learning and creation of knowledge between supply chain partners. The use of shared data warehouse and data/text mining, repository database and decision support systems, digital documents and archives and group decision support systems enables creation of inter-firm intelligence (Zhang \& Cao, 2018). Zhang and Cao (2018) examined a third dimension of IOS use, IOS Use for Integration, which explored the extent to which IOS is used to facilitate coupling of electronic processes between supply chain partners. Most IOS come with several features that are activated based on management strategic decisions and capabilities. The core of IOS is bringing disparate business components together. However, moving data at rest into forms that generate unique assets goes beyond mere aggregation. Supply chain management integration is a capability that provides an opportunity for a firm to distinct itself (Barki \& Pinsonneault, 2005). Thus, in this study, the integration dimension of SCM capabilities is considered as part of the organizational capabilities that influence efficient, reliable and flexible supply chain operation. IOS use compels a firm within the supply network to build the needed capabilities to achieve improved supply chain performance. 
SCM capabilities are deemed important for firms to get maximum benefits from their IOS use.IT supply chain capabilities encompass four broad inter-firm SCM capabilities namely information exchange, inter-firm activity integration, coordination, and supply chain responsiveness (Wu et al., 2006). These capabilities are adapted in our study as supply chain information exchange, supply chain integration, supply chain coordination, and supply chain responsiveness. Supply chain information exchange capability refers to the ability of a firm to share knowledge with its supply chain partners in an effective and efficient manner (Wu et al., 2006). The ability to share the right information with the right supply chain partners when required is an important capability necessary for effective SCM (Shore \& Venkatachalam, 2003; Wu et al., 2006). Supply chain integration capability refers to the ability of a firm to align its activities and technologies with its supply chain partners in an attempt to reap targeted strategic benefits (Bowersox et al., 1999; Wu et al., 2006). Supply chain coordination capability $n$ refers to the ability of a firm to effectively coordinate varying supply chain activities and transactions with supply chain partners (Sahin \& Robinson, 2002; Wu et al., 2006). Supply chain responsiveness capability in this study refers to the extent to which channel members are quickly able to respond to changes emanating from their supply chain partners and the business environment (Wu et al., 2006).

Finally, supply chain performance is a measure of how well the supply chain is able to meet its functional objectives (Sezen, 2008; Won Lee et al., 2007). Three dimensions of supply chain performance identified in the literature include; reliability, efficiency (cost containment) and flexibility (Sezen, 2008; Won Lee et al., 2007). These three forms of performance are explored in this study. Reliability performance refers to how well the organization is able to meet customer orders, minimize stock outs and eliminate other operational supply chain bottlenecks (Sezen, 2008; Won Lee et al., 2007). Efficiency performance refers to how well firms are able to minimize their supply chain costs (Sezen, 2008). Flexibility Performance measures how well organizations are able to deliver customized and differentiated product offerings to their customers as a result of their supply chain (Sezen, 2008).

The research model for the study and hypotheses are presented in Figure 1. Following previous studies, the three major constructs were conceptualized at the second-order level (Koçoğlu et al., 2011; Sezen, 2008; Zhang \& Cao, 2018). 


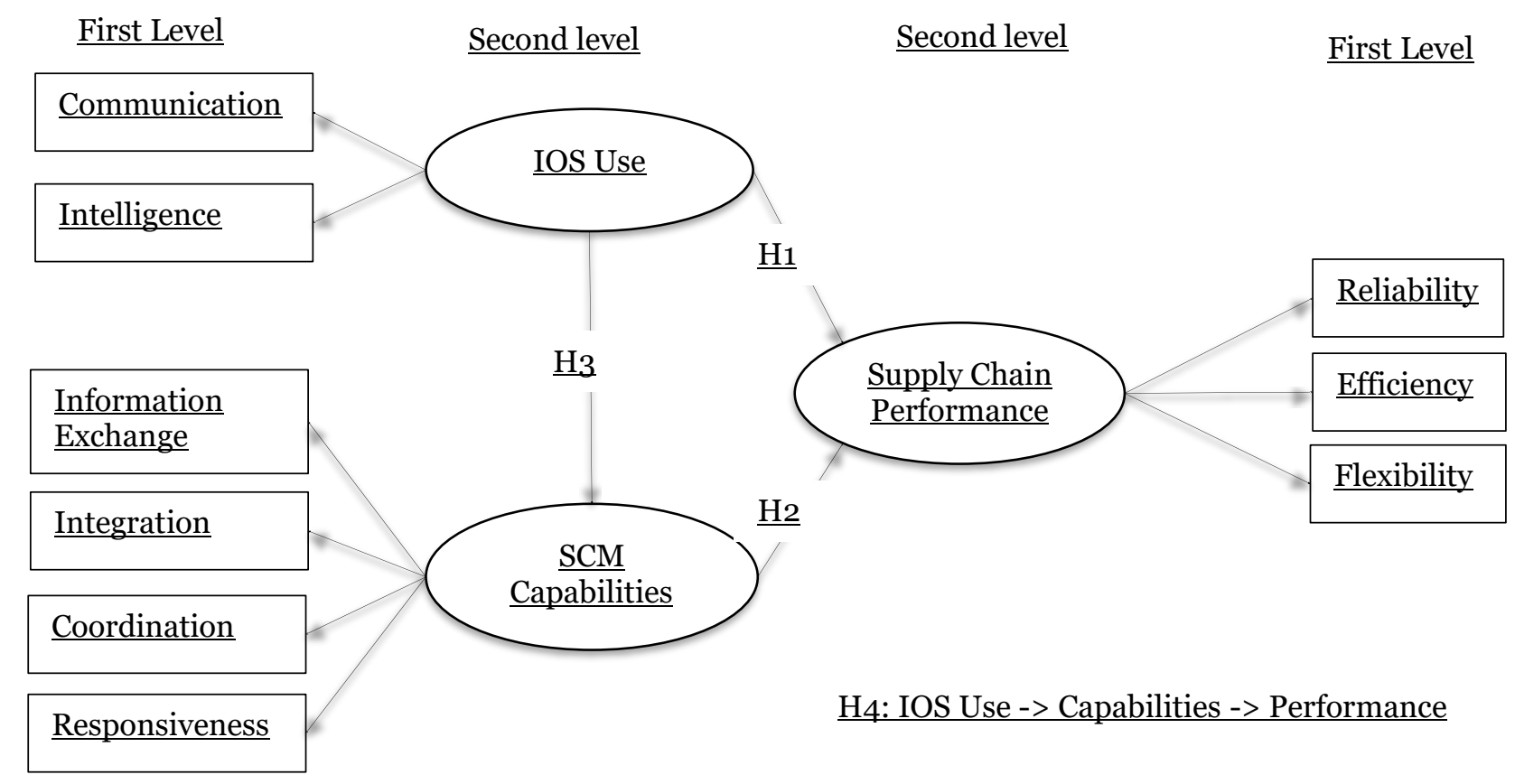

Figure 1. Research Model

\subsection{IOS use and supply chain performance}

The RBV theory suggests that resource use that results in the creation of assets that are rare, valuable and imperfectly imitable and controlled by the firm will enable the firm to outperform its competitors (Barney et al., 1991). IOS, an organizational resource, can help in creating superior firm and supply chain performance in several ways. First, IOS can be viewed as firmwide and cross-firm information systems resources which can be leveraged for identifying extra revenue generating streams from the supply chain network (Hartono et al., 2010; Agbenyo et al., 2018). Additionally, IOS can serve as a tool through which other resources can be more efficiently combined to achieve superior performance. Further, IOS can serve as a source through which organizations gain access to valuable external resources. The RBV theory thus supports the proposition that IOS use can enhance supply chain performance.

IOS enables the sharing of quality information to achieve higher operational supply chain performance (Hartono et al., 2010). IOS use enables seamless sharing of real-time information so that supply chain partners can appropriately respond to changes in the supply chain and the wider business environment. IOS can be used to achieve greater coordination of activities and joint supply chain planning, which allow firms to maintain lower inventory levels across the supply 
chain (Lee et al., 2014; Zhang \& Cao, 2018). This will not only enable the firm be flexible in meeting its customer needs but also a reliable partner to its supply chain network. For instance, firms can obtain greater visibility into stock levels of key suppliers and distributors through IOS use. This ensures a better chance to avoid stock-outs which lower supply chain performance (Lee et al., 2014). IOS use also enables accurate and timely transfer of customer demand information across the supply chain. Such an effective use of IOS enables firms to avoid the demand distortion (Kim et al., 2012; Lee et al., 2014). This minimizes supply chain inefficiencies leading to overall enhanced performance. Based on the preceding discussions, it is hypothesized that:

\section{H1: Inter-organization systems use is positively related to supply chain performance}

\subsection{SCM capabilities and supply chain performance}

From the perspective of the RBV, controlling valuable resources is not enough to obtain sustained competitive advantage. It is incumbent on firms to develop capabilities to enable effective configuration of resources to meet changing market conditions to achieve sustained competitive advantage (Barney, 1991; Teece, 1997). Morash and Lynch (2002) note that supply chain capabilities together with resources are the building blocks for supply chain strategy and are a potential source of competitive advantage. Supply chain capabilities refer to the ability of an organization to identify, utilize, and assimilate both internal and external resources/information to facilitate the entire supply chain activities (Wu et al., 2006). The RBV suggests that firms that develop higher organizational and SCM capabilities will be able to attain superior performance (Barney et al., 1991; Wu et al., 2010).

The empirical evidence also supports the proposition that SCM capabilities can result in performance improvements. For instance, Liao and Kuo (2014) observed that supply chain capabilities had a significant impact on firm performance. Yu et al. (2018) asserted that supply chain capabilities had a significant impact on financial performance, with the positive effect of coordination and responsiveness being confirmed. Additionally, it was found that firms with greater SCM capabilities in terms of IT enabled integration, responsiveness and flexibility achieved higher competitive advantage (Wang et al., 2006). Hartono et al. (2010) noted that higher levels of information sharing resulted in higher levels of operational supply chain performance. This is because a firm capable of effectively utilizing its data exchange systems in its coordination and integration with its supply chain partners would respond timely to market 
changes. Thus, the four SCM capabilities help firms achieve higher product availability, just-intime delivery and reduced inventory levels needed to ensure reliable, flexible and efficient supply chain operations (Rajaguru \& Matanda, 2013). This leads us to hypothesize that:

H2: Supply chain management capabilities is positively related supply chain performance

\subsection{IOS use and SCM capabilities}

The RBV theory stresses that firms can leverage on their resources to develop unique organizational capabilities which cannot be copied by their competitors (Wu et al., 2010). The literature on RBV suggests that capabilities can be built through complex interactions between the firm's resources (Amit \& Schoemaker, 1993). Such resources can be considered as the building blocks for achieving higher levels of organizational capabilities. IOS resources can be leveraged and deployed in unique ways to create SCM capabilities for firms.

Previous studies have viewed IOS as information systems resources that can be leveraged to create higher level capabilities for firms. For instance, it was revealed that IOS appropriation (adoption and use of IOS) results in increased supply chain collaboration (Zhang \& Cao, 2018). Effective IOS appropriation has a significant impact on the creation of supply chain capabilities (Agbenyo et al. 2018). IOS use to integrate firm's operation internally and externally also enables intelligent joint decision making by multiple firms to achieve higher SCM capabilities (Rajaguru \& Matanda, 2013). Additionally, Wang and Wei (2007) observed that IOS enabled virtual integration created supply chain visibility, whilst Yu et al. (2018) observed that data driven supply chains had a significant impact on supply chain capabilities. Hence, we expect that:

H3: Inter-organization systems use is positively related to supply chain management capabilities

\subsection{IOS use, SCM capabilities and supply chain performance}

RBV proposes that valuable resources alone may not be enough to generate sustained competitive advantage and superior performance for firms. The resources must be combined, deployed and leveraged in unique and effective ways to create distinctive competencies and capabilities which are tied semi-permanently to the firm which serve as the basis for superior 
performance (Barney, 1991). In line with the RBV, we anticipate that the IOS use for communication and intelligence can be leveraged to create higher organizational capabilities for managing the supply chains, which would enable firms to achieve higher levels of supply chain performance.

Some studies have noted that IOS use does not directly result in the creation of superior performance. Yu et al. (2018) observed that data driven supply chains first resulted in the creation of supply chain capabilities, and then subsequently leads to the higher performance. Whilst the direct effect of IOS use on supply chain performance has been observed in previous studies (Hartono et al., 2010; Lee et al., 2014), prior studies have revealed that some firms have heavily invested in IOS and not reaped significant benefits. We postulate that SCM capabilities play an intervening role on the relationship between IOS use and supply chain performance. This is because non-routine use of IOS for communication and business intelligence leads to the development of skills that leads to non-traditional use of IOS. It is expected that using IOS results in the creation of SCM capabilities for firms, which then translates into improved supply chain performance. Therefore, we argue that:

H4: Supply chain management capabilities mediate the effect of inter-organization systems use on supply chain performance

Additionally, firm size (annual revenue and number of employees), firm experience (years of operation) and industry type are explored as control variables that could influence supply chain performance of firms. Larger firms may be able to control more resources and capabilities which could enable them to achieve higher levels of supply chain performance. Similarly, firms that have been in operation for longer may have gained greater knowledge, capabilities and relationships that can be leveraged for higher supply chain performance. The relationship between the constructs may also vary based on industry.

\section{Methodology}

The measurement instrument for the constructs was obtained from previous studies and adapted to suit the context of this study. IOS use from Zhang and Cao (2018), SCM capabilities from Wu et al. (2006), and supply chain performance from Koçoğlu et al. (2011) and Won Lee et al. (2007). The survey instrument was pilot tested and refined (see appendix for final instrument). 
For the main study, a survey of respondents made up of key top management members from firms in Ghana that use IOS in their operations was conducted. The data collection targeted manufacturers and their key supply chain partners (distributors of FMCG). In Ghana, the major manufacturers of FMCG and their key distributors typically use IOS to share inventory and sales information, as well as to plan and execute restocking decisions. Questionnaires were delivered to about 500 firms with a cover letter detailing the purpose of the study. After several rounds of follow-ups, 193 usable responses were successfully retrieved. Power analysis was conducted using a recommended medium effect size of 0.3 , a minimum statistical power of 0.8 , and a probability of error of 0.05 (Cohen, 2013), with the results revealing that a minimum sample size of 82 responses will be required for the results to attain statistical power. The results of the data analysis are presented next.

\section{Sample Demographic}

Analysis of the demographic data collected revealed that $25.9 \%$ of the respondents were from firms who manufacture FMCG, with $71.0 \%$ being major distributors and large retailers of FMCG. In terms of maturity of firms, $37.8 \%$ had been in operation for up to 10 years, $25.9 \%$ for 11 to 20 years, and about $36.3 \%$ more than 20 years. Finally, $47.6 \%$ of firms had revenue levels

of one million Ghana cedis or more (approximately US\$186,219), with about $48.2 \%$ having less than one million Ghana cedis. Firms with less than 10 employees accounted for $25.4 \%$ of the data, $30.5 \%$ reporting employees of more than 50 and $44.1 \%$ not reported.

\section{Analysis and results}

\subsection{Measurement model assessment}

To assess the measurement model, we followed the guidelines proposed by Hair et al. (2019). The analysis was conducted using partial least squares structural equation (PLS-SEM) approach, using SmartPLS version 3 (Ringle et al., 2015). First, indicator loadings were assessed to determine if they exceeded the minimum cut-off criteria of 0.708 . This serves as an indication that the construct explains more than 50 per cent of the indicator's variance, thus providing acceptable item reliability. All items possessing factor loadings less than 0.708 were dropped (APCOM3; APINTL4, APINTL5 and SCCOD1), with the remaining items meeting this threshold as can be seen from the results in bold in Table 3. 
Table 3

Loadings and cross-loadings

\begin{tabular}{|c|c|c|c|c|c|c|c|c|c|}
\hline & $\mathrm{OM}$ & INTL & CORD & INFX & INTG & RES & EFF & FLX & $\mathrm{EL}$ \\
\hline M1 & 4 & 511 & 0.450 & 4 & 0.349 & 0.547 & 472 & .529 & .488 \\
\hline $\mathrm{OM} 2$ & 888 & 653 & 0.558 & 565 & 397 & 584 & 472 & .479 & 498 \\
\hline $\mathrm{AP}$ & 859 & 569 & 0.518 & 504 & 341 & 545 & 522 & 559 & 425 \\
\hline APCOM5 & .890 & 682 & 0.56 & 596 & 3 & 532 & 562 & 530 & .557 \\
\hline APINTL1 & 0.588 & 830 & 0.48 & 4 & 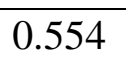 & 6 & 8 & 478 & 525 \\
\hline $\mathrm{AF}$ & 0.668 & 97 & 0.46 & 5 & 4 & 556 & 445 & .465 & .502 \\
\hline $\mathrm{A}$ & 0.606 & 0.881 & 0.514 & 3 & 0.441 & 1 & 6 & 9 & 5 \\
\hline SC & 480 & 0.445 & 0 & 9 & 0.479 & 2 & 9 & 3 & 6 \\
\hline & & & 0 & & & 0 & 523 & & .470 \\
\hline D4 & 449 & 454 & 0.823 & 506 & 0.405 & 0.466 & 461 & .371 & .375 \\
\hline D5 & 448 & 411 & 6 & 589 & 512 & 563 & 516 & 379 & .486 \\
\hline $\mathrm{X} 1$ & 541 & 518 & 609 & 363 & 531 & 592 & 559 & 473 & 585 \\
\hline $\mathrm{SCD}$ & 508 & 500 & 0643 & 380 & .452 & 641 & 455 & .508 & .551 \\
\hline $\mathrm{SCIN}$ & 546 & 532 & 625 & 856 & 168 & .667 & 0.526 & .535 & .548 \\
\hline $\mathrm{CCIN}$ & 7 & 522 & 606 & 350 & 5 & 31 & 599 & .575 & .588 \\
\hline SCINTG1 & 1 & 0.498 & 0.572 & 2 & 0.855 & 5 & 9 & 7 & 549 \\
\hline 2 & 2 & 2 & 0 & 5 & 0.896 & 4 & 5 & .361 & 487 \\
\hline $\mathrm{SC}$ & + & & & & & 2 & 8 & 3 & 500 \\
\hline $\mathrm{SC}$ & 4 & & & & & & & 2 & 454 \\
\hline SCR & 55 & 6 & 0 & & & & 5 & 3 & .571 \\
\hline SCR & 169 & 8 & 0 & & & & 6 & 9 & 478 \\
\hline$\overline{S C R}$ & 1 & 3 & U & 9 & & & 9 & 0 & 81 \\
\hline SCR & 592 & 8 & U & 9 & 5 & 4 & 5 & 0 & 629 \\
\hline$\overline{\mathrm{SI}}$ & 0.450 & 0.483 & $0 .{ }^{2}$ & 0 & 0.422 & 20 & 9 & 9 & .000 \\
\hline SPEI & 0.482 & 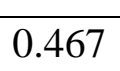 & 0 & 5 & 0.413 & 4 & 6 & 52 & 0.549 \\
\hline $\mathrm{SP}$ & 4 & 5 & 0.5 & 8 & 0 & 2 & 4 & 0.588 & 0.526 \\
\hline SPEFF4 & 0.571 & 0.544 & 0.599 & 0.588 & 0.466 & 0.583 & 0.867 & 0.597 & 0.597 \\
\hline SPFLX1 & 395 & 0.435 & 0.385 & 0.444 & 0.300 & 0.560 & 0.586 & 0.818 & 0.547 \\
\hline $\mathrm{SF}$ & 433 & 447 & 0.341 & 0.376 & 0.285 & 0.484 & 0.444 & 0.818 & 0.433 \\
\hline
\end{tabular}




\begin{tabular}{l|l|l|l|l|l|l|l|l|l}
\hline SPFLX3 & 0.496 & 0.531 & 0.520 & 0.578 & 0.441 & 0.550 & 0.537 & $\mathbf{0 . 8 6 9}$ & 0.601 \\
\hline SPFLX4 & 0.556 & 0.506 & 0.534 & 0.519 & 0.359 & 0.549 & 0.616 & $\mathbf{0 . 7 7 6}$ & 0.518 \\
\hline SPFLX5 & 0.590 & 0.509 & 0.509 & 0.575 & 0.365 & 0.571 & 0.579 & $\mathbf{0 . 8 5 2}$ & 0.578 \\
\hline SPREL1 & 0.532 & 0.561 & 0.500 & 0.542 & 0.535 & 0.649 & 0.557 & 0.556 & $\mathbf{0 . 8 4 3}$ \\
\hline SPREL2 & 0.519 & 0.520 & 0.485 & 0.530 & 0.425 & 0.587 & 0.530 & 0.525 & $\mathbf{0 . 8 4 2}$ \\
\hline SPREL3 & 0.497 & 0.533 & 0.555 & 0.591 & 0.483 & 0.563 & 0.532 & 0.560 & $\mathbf{0 . 8 9 6}$ \\
\hline SPREL4 & 0.391 & 0.474 & 0.517 & 0.577 & 0.490 & 0.554 & 0.530 & 0.563 & $\mathbf{0 . 8 2 5}$ \\
\hline SPREL5 & 0.382 & 0.404 & 0.467 & 0.473 & 0.433 & 0.466 & 0.571 & 0.479 & $\mathbf{0 . 7 0 9}$ \\
\hline
\end{tabular}

Next, the internal consistency reliability of the constructs was examined using the Composite Reliability and Cronbach Alpha values. Composite reliability values ranged from 0.894 to 0.928 , whilst Cronbach Alpha values ranged from 0.826 to 0.896, both meeting recommended benchmarked thresholds of 0.7 (Hair et al., 2019). The convergent validity of the constructs was then assessed. Convergent validity is the extent to which the construct converges to explain the variance of its items. The metric used for evaluating a construct's convergent validity is the average variance extracted (AVE) for all items on each construct, with an AVE 0.50 or higher deemed acceptable. The AVE values ranged from 0.657 to 0.762 , meeting this requirement. The summary of the tests for convergent validity are presented in Table 4 below.

Table 4.

Tests of convergent validity

\begin{tabular}{l|c|c|c}
\hline Construct & $\begin{array}{c}\text { Cronbach's } \\
\text { Alpha }\end{array}$ & $\begin{array}{c}\text { Composite } \\
\text { Reliability }\end{array}$ & AVE \\
\hline Supply Chain Coordination (CORD) & 0.869 & 0.905 & 0.657 \\
\hline Supply Chain Information Exchange (INFX) & 0.885 & 0.921 & 0.743 \\
\hline Supply Chain Integration (INTG) & 0.891 & 0.924 & 0.754 \\
\hline Supply Chain Responsiveness (RESP) & 0.842 & 0.894 & 0.679 \\
\hline Efficiency Performance (EFF) & 0.887 & 0.922 & 0.747 \\
\hline Flexibility Performance (FLX) & 0.884 & 0.915 & 0.684 \\
\hline Reliability Performance (REL) & 0.881 & 0.914 & 0.681 \\
\hline IOS Use for Communication (COM) & 0.896 & 0.928 & 0.762 \\
\hline IOS Use for Intelligence (INTL) & 0.826 & 0.896 & 0.742 \\
\hline
\end{tabular}


Next, discriminant validity of the constructs was assessed, which is the extent to which a construct is empirically distinct from other constructs in the structural model. Discriminant validity can be assessed by comparing the square root of the AVE for each factor against the correlation of constructs against each other, with the former required to be higher than the latter (Fornell \& Larcker, 1981). In Table 5, the bold diagonal figures represent square roots of AVEs whilst the off-diagonal figures represent correlation among constructs. It can be seen that the bold diagonal values are all greater than the off-diagonal ones, confirming adequate discriminant validity.

Table 5.

Fornell-Larcker test results

\begin{tabular}{l|l|l|l|l|l|l|l|l|l}
\hline & CORD & INFX & INTG & RESP & EFF & FLX & REL & COM & INTL \\
\hline CORD & $\mathbf{0 . 8 1 0}$ & & & & & & & & \\
\hline INFX & 0.750 & $\mathbf{0 . 8 6 2}$ & & & & & & & \\
\hline INTG & 0.594 & 0.567 & $\mathbf{0 . 8 6 8}$ & & & & & & \\
\hline RESP & 0.679 & 0.734 & 0.677 & $\mathbf{0 . 8 2 4}$ & & & & & \\
\hline EFF & 0.628 & 0.621 & 0.476 & 0.622 & $\mathbf{0 . 8 6 4}$ & & & & \\
\hline FLX & 0.557 & 0.607 & 0.426 & 0.658 & 0.670 & $\mathbf{0 . 8 2 7}$ & & & \\
\hline REL & 0.613 & 0.659 & 0.574 & 0.685 & 0.658 & 0.651 & $\mathbf{0 . 8 2 5}$ & & \\
\hline COM & 0.600 & 0.625 & 0.413 & 0.632 & 0.581 & 0.600 & 0.565 & $\mathbf{0 . 8 7 3}$ & \\
\hline INTL & 0.568 & 0.603 & 0.555 & 0.720 & 0.570 & 0.589 & 0.606 & 0.722 & $\mathbf{0 . 8 6 2}$ \\
\hline
\end{tabular}

However, it has been argued that the Fornell-Larcker criterion is not a strong metric of discriminant validity, with the heterotrait-monotrait (HTMT) ratio of the correlations proposed as a more stringent alternative (Hair et al., 2019; Henseler et al., 2015; Voorhees et al., 2016). The HTMT is defined as the mean value of the item correlations across constructs relative to the (geometric) mean of the average correlations for the items measuring the same construct, with HTMT values of less than 0.90 recommended (Henseler et al., 2015). From Table 6, the model passes this test as the highest HTMT value was 0.867 . This confirms the discriminant validity of the constructs. 
Table 6

HTMT test results

\begin{tabular}{l|l|l|l|l|l|l|l|l|l}
\hline & CORD & INFX & INTG & RESP & EFF & FLX & REL & COM & INTL \\
\hline CORD & & & & & & & & & \\
\hline INFX & 0.847 & & & & & & & & \\
\hline INTG & 0.669 & 0.637 & & & & & & & \\
\hline RESP & 0.788 & 0.848 & 0.785 & & & & & & \\
\hline EFF & 0.711 & 0.699 & 0.534 & 0.718 & & & & & \\
\hline FLX & 0.626 & 0.681 & 0.479 & 0.759 & 0.754 & & & & \\
\hline REL & 0.694 & 0.746 & 0.648 & 0.796 & 0.747 & 0.734 & & & \\
\hline COM & 0.676 & 0.701 & 0.460 & 0.726 & 0.651 & 0.673 & 0.633 & & \\
\hline INTL & 0.670 & 0.704 & 0.649 & 0.867 & 0.668 & 0.688 & 0.711 & 0.836 & \\
\hline
\end{tabular}

\subsection{Structural model analysis results}

After confirming the soundness of the measurement model, we proceeded to assess the structural model and hypothesized relationships. Before assessing the structural relationships, collinearity was examined to ensure it does not bias the results. This was done by assessing the variance inflation factor (VIF) of the latent variables. The VIF values ranged from 1 to 2.199 which meets the requirement of being less than 3 (Hair et al., 2019). Next the model's in-sample explanatory power was assessed by examining the $\mathrm{R}^{2}$ values of the endogenous variables. As a guideline, $\mathrm{R}^{2}$ values of $0.75,0.50$ and 0.25 can be considered substantial, moderate and weak (Hair et al., 2011). SCM capabilities had an $\mathrm{R}^{2}$ value of 0.533 whilst supply chain performance had an $\mathrm{R}^{2}$ value of 0.677 , which translates into moderate explanatory power of the model. Another means to assess the PLS path model's predictive accuracy is by calculating the $Q^{2}$ value (Geisser, 1974; Stone, 1974). As a rule of thumb, $Q^{2}$ values should be larger than zero for a specific endogenous construct to indicate predictive power of the structural model for that construct (Hair et al., 2019). $Q^{2}$ values ranged from 0.275 to 0.679 , confirming the predictive relevance of the model.

To ascertain whether the direct hypothesized paths were supported, we examined the path coefficients and t-values for each hypothesized direct path. The results revealed that the effect of IOS use on supply chain performance was found to be positive and significant $(\beta=0.302 ; \mathrm{t}=$ 4.843; $\mathrm{p}<0.0001)$, meaning that hypothesis 1 was supported. The effect of SCM capabilities on 
supply chain performance was likewise significant $(\beta=0.563 ; \mathrm{t}=9.340 ; \mathrm{p}<0.0001)$. Thus, hypothesis 2 was supported. The effect of IOS use on SCM capabilities was positive and significant $(\beta=0.730 ; \mathrm{t}=16.007 ; \mathrm{p}<0.001)$, meaning hypothesis 3 was supported.

To assess the mediating effect of SCM capabilities on the effect of IOS use on supply chain Performance, the indirect effect was examined as recommended (Nitzl et al., 2016). The results revealed that SCM capabilities significantly mediated the effect of IOS use on supply chain performance as hypothesized $(\beta=0.411 ; \mathrm{t}=7.645 ; \mathrm{p}<0.001)$, meaning hypothesis 4 was supported. To ascertain the type of mediating effect it was, the direct effect of IOS Use on supply chain performance (with the mediator) $(\beta=0.714 ; \mathrm{t}=15.576 ; \mathrm{p}<0.001)$ was compared to the indirect effect of IOS Use on supply chain performance $(\beta=0.411 ; t=7.645 ; p<0.001)$. Given that both direct and indirect effects are positive and significant, it is concluded that SCM capabilities serve as a complementary partial mediator of the effect of IOS Use on supply chain performance. This means that a portion of the effect of IOS Use on supply chain performance is mediated through SCM capabilities and a portion directly impacts supply chain performance independent of SCM capabilities. The results of the structural model analysis are presented in Table 7 .

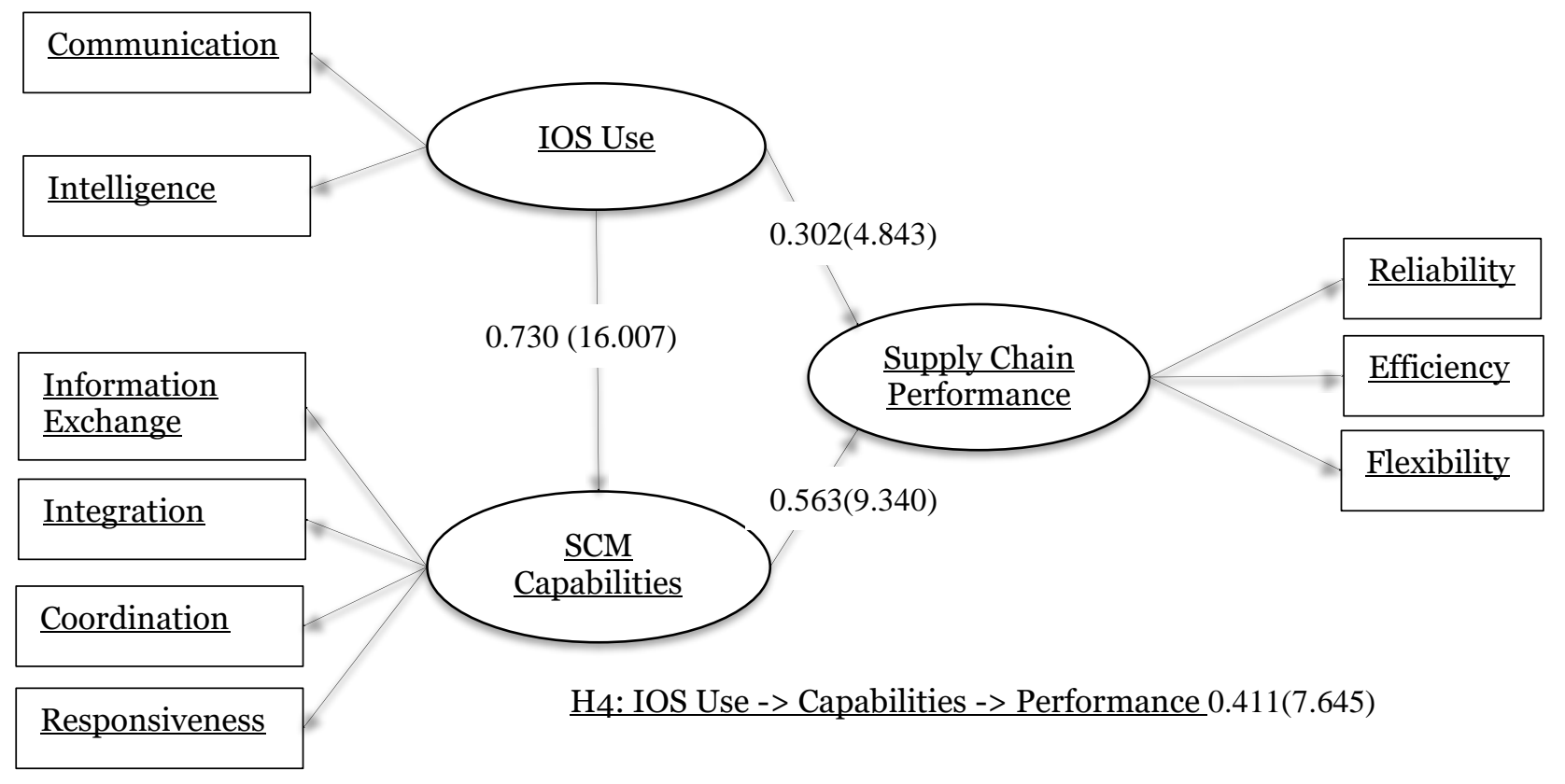

Figure 2. Research Model 
Table 7

Hypotheses results

\begin{tabular}{c|l|c|c|c|c}
\hline Hs & \multicolumn{1}{|c|}{ Hypothesis } & Effect size & T Statistics & P values & Decision \\
\hline H1 & $\begin{array}{l}\text { IOS use } \rightarrow \text { Supply Chain } \\
\text { Performance }\end{array}$ & 0.302 & 4.843 & 0.001 & Supported \\
\hline H2 & $\begin{array}{l}\text { Supply Chain Capabilities } \rightarrow \\
\text { Supply Chain Performance }\end{array}$ & 0.563 & 9.340 & 0.001 & Supported \\
\hline H3 & $\begin{array}{l}\text { IOS use } \rightarrow \text { Supply Chain } \\
\text { Capabilities }\end{array}$ & 0.730 & 16.007 & 0.001 & Supported \\
\hline H4 & $\begin{array}{l}\text { IOS use } \rightarrow \text { Supply Chain } \\
\text { Capabilities } \rightarrow \text { Supply Chain } \\
\text { Performance }\end{array}$ & 0.411 & 7.645 & 0.001 & Supported \\
\hline
\end{tabular}

Regarding the control variables, it was observed that industry type $(\beta=0.126 ; \mathrm{t}=2.570 ; \mathrm{p}<$ 0.01) had a positive and significant effect on the level of supply chain performance of firms. This suggests that the supply chain performance levels of the responding firms varied based on their industry. Employee size $(\beta=0.011 ; \mathrm{t}=0.230)$, revenue of firms $(\beta=-0.054 ; \mathrm{t}=1.124)$ and firm experience $(\beta=0.016 ; t=0.325)$ did not significantly affect supply chain performance.

\section{Discussions}

The results of the study provide initial verification of the effectiveness of the IT artefact in explaining the level of supply chain performance of firms. The results provide empirical support for prior studies on the effectiveness of IOS in predicting the level of supply chain performance of firms (Asamoah et al., 2019; Lee et al., 2013; Hartono et al., 2010).

The findings of the study revealed that the effect of IOS use on SCM capabilities was positive and significant. A firm's integrated supply chain management systems, that is utilized for communication also provide an opportunity to glean insights from within and outside the organization. The use of IOS exclusively for communication and business intelligence results under-utilization of company results. Such utilization will lead to accumulation of knowledge that is unique to the firm. The study results demonstrate that IOS communication use is intertwined with its use for business intelligence. Effective use of the technical features of IOS reduces data silos and would increase logistical efficiency and flexibility in the supply chain context (Narasimhan \& Kim, 2001). This indicates that firms that use IOS at a higher level can 
achieve higher levels of supply chain information exchange, supply chain integration, supply chain coordination, and supply chain responsiveness. This confirms that, simultaneous utilization of communication and intelligence functionalities of IOS leads to enhanced skills development needed to create imitable or non-transferable assets from IOS. This is consistent with findings on IOS use in the context of supply chain (Agbenyo et al., 2018; Rajaguru \& Matanda, 2013). Firms should invest in effective utilization of communication and intelligence functionalities of IOS to enhance their SCM capabilities.

The findings also reveal that IOS use positively and significantly impacts on the supply chain performance of firms. This indicates that firms that used IOS for communication and for business intelligence purposes were able to significantly improve their efficiency, reliability and flexibility performance. This agrees with previous studies like Lee et al. (2014) and Hartono et al. (2010) who had observed positive and significant effects of IOS use on supply chain performance. Firms should aim at improving their level at which they use IOS to enhance their supply chain performance.

The results further indicate that, higher SCM capabilities can be leveraged to propel attainment of higher levels of supply chain performance. It suggests that it is not sufficient to integrate technical systems. The business processes and practices within and across the firm should integrated. Routine use of IOS for information flow may not be sufficient to realize the full potential of IOS unless management encourages the development of capabilities that create unique advantage (Williamson et al., 2004). SCM capabilities developed through IOS use are useful building blocks that aid in the achievement of greater reliability, efficiency and flexibility in their supply chains. This is because enhanced capabilities ensure that information captured and processed by IOS are reliable and timely. The resulting high quality information supports operational supply chain performance (Hartono et al., 2010). Coordination and responsiveness capabilities increase the visibility of the IOS in the firm and subsequently positively impact the performance of supply chain systems (Lee et al., 2014).

The results reveal that IOS use does not only directly enhance supply chain performance, but indirectly enhances it through the achievement of SCM capabilities. Because of the networked nature of the economies most firms have to compete in, it has become imperative for all firms to have IT-enabled supply chain (Gunasekaran \& Ngai, 2004). However, in addition to using the 
functionalities of IOS, it is critical for users in the organizations to develop rare skills in the integrations of disparate insights and be agile in the response in dealing with their networked partners. The results of the study provide empirical support to the intricate interplay of IOS use and IOS capabilities in the context of supply chain. This enhances our understanding of how IOS use enhances supply chain performance of firms. In line with the RBV theory, it was observed that IOS use enables firms to develop unique capabilities for better managing their supply chains (supply chain information exchange, supply chain responsiveness, supply chain integration and supply chain coordination), and these capabilities are leveraged for attainment of higher supply chain performance. Further examination of the mediation role of SCM capabilities on the relationship between IOS Use and supply chain performance revealed a complementary partial mediation role of SCM capabilities. This indicates that IOS use partly enhances supply chain performance directly, and partly enhances it through enhanced SCM capabilities. Thus, firms that can leverage SCM capabilities developed from IOS use can further enhance their supply chain performance. These findings on the mechanisms through which IOS enhance supply chain performance of firms extend the frontiers of RBV within the context of IOS and SCM.

With regards to the control factors, the findings revealed that industry of firms had a significant effect on the level of supply chain performance of firms. It was interesting to note that wholesalers and retailers of FMCG had significantly higher levels of supply chain performance $($ Mean $=3.98)$ compared to manufacturers of FMCG $($ Mean = 3.81). The differences in the level of supply chain performance based on industry suggest that the effect of IOS use and SCM capabilities on supply chain performance may vary based on industry. Thus, firms need to look at the specific industry of operation to identify what unique assets can be created with the use of IOS. Further research into the relationships between IOS Use, SCM capabilities and supply chain performance for different industries would provide practical insights for managers. In the context of this study, the size of the firm or the number of years of its existence do not provide any indication that a firm's SCM performance is a function of those factors. One potential explanation of the results be the developing economy context in which this study was conducted. Most firms in the developing economics are still in the nascent stages of IOS assimilation such that there exist no differences among them. In addition, the high percentage of missing response for the firm size may limit the strength the findings on firm size and that the results could be different if the response improves in future research. 


\subsection{Theoretical contributions}

The research makes some theoretical contributions. First, the study uses the RBV theory to theorize and elucidate the complex interaction between IOS Use, SCM capabilities and supply chain performance. The study findings highlight the internal organizational resources and external leverage mechanisms for achieving competitive advantage that is manifest in supply chain performance. It was established that IOS are valuable information resources that can be used for communication and intelligence purposes to create SCM capabilities, which can be leveraged for higher supply chain performance. Although, prior research has established that IOS use and SCM capabilities individually directly impact supply chain performance, the current study highlights the dependencies between the two factors and how they influence performance. The results of the study thus extend the frontiers of RBV within the context of IOS use and SCM in confirming that the valuable information resources coupled with SCM capabilities occasion superior performance.

Second, the study empirically presents new insights on the outcomes of IOS use. Whilst some studies have observed significant positive effects of IOS on performance (e.g. Hartono et al., 2010, Lee et al., 2014), others have indicated that firms do not always benefit from their adoption and use of integrated systems (Rivard \& Lapointe, 2012). The current study unravels the relationship between IOS use and performance by identifying development of capabilities as an important intervening variable that influences how firms can benefit from their IOS use especially in the context of supply chain. Firms that leverage their information exchange, integration, coordination and responsiveness capabilities obtained from their IOS use stand to achieve superior supply chain performance. Firms that are unable to leverage these necessary SCM capabilities obtained through their IOS use may observe only marginal improvements in their supply chain performance.

Third, the study also contributes to IOS research by proposing and empirically validating a new and more parsimonious two-prong conceptualization of IOS Use. Whilst previous studies (Agbenyo et al., 2018; Asamoah et al., 2019; Zhang \& Cao, 2018) have examined IOS Use with three dimensions (Communication, Integration and Intelligence), we propose that Communication and Intelligence sufficiently measure IOS Use, with aspects of IOS Use for 
Integration captured by the two dimensions. Additionally, using IOS for business process integration and intra and inter firm integration can be better thought of as a capability (Chang, 2011; Wu et al., 2006), which has been done in our study. Future research on IOS can adopt this new conceptualization of IOS Use.

\subsection{Implications for Practice}

There are some important implications of the study for practice. The finding that IOS use positively influences supply chain performance suggest that, managers of organizations should devote significant resources to attaining higher levels of IOS use for communication and intelligence functionalities of their IOS. Additionally, IOS use directly results in the development of important SCM capabilities for firms, enabling them to obtain greater information exchange, coordination, integration and responsiveness capabilities.

The study also highlights to managers and other practitioners the important role of SCM capabilities in firms' IOS implementation results. Whereas IOS use can directly enhance the supply chain performance of firms, SCM capabilities were identified as additional avenue through which IOS can enhance supply chain performance. This means that firms can leverage on higher levels of information exchange, integration, coordination and responsiveness capabilities occasioned by IOS use to further enhance their supply chain performance. Failure to do this would result in firms witnessing only marginal improvements in supply chain performance. Thus, when constraint by resources, investments should be made in developing capabilities in coordination, integration and agility in the use of IOS for information exchange.

Based on the complex interrelationship of IOS use and SCM capabilities in driving supply chain performance, it is important for managers and business practitioners to aim at concurrently managing and deploying their IOS implementations and SCM capabilities, as this should create highest possible benefits in terms of supply chain performance.

\subsection{Limitations and Future Research}

There were some limitations to the work. IOS use, SCM capabilities, and supply chain performance were conceptualized as second-order reflective constructs having first order dimensions, with the relationship between constructs explored at the second-order level to prevent the model becoming overly complex. Future research could further explore the intricate 
dynamics between the constructs at the first-order level. Such studies may provide further insights for research and practice about the effect of IOS use on specific dimensions of SCM capabilities and supply chain performance. Future studies can also explore into greater detail the complementarity of IOS Use and SCM capabilities in driving supply chain performance. The complementary effect may not be linear and further examination of a potential non-linear relationship would provide additional insights. Also, as the study utilized data from only one context - Ghana in Sub-Saharan Africa, future research may explore the phenomenon examined in this research over multiple contexts.

\section{Conclusions}

The study was conducted to investigate the direct and indirect effect of IOS use on the supply chain performance of firms. SCM capabilities were proposed as a mediator of the effect of IOS use on supply chain performance. Analysis of survey responses of managers of various firms reveal that IOS use enhances both SCM capabilities and supply chain performance directly. SCM capabilities was also found to play a complementary partial mediation role in the relationship between IOS use and supply chain performance, meaning that IOS use partly enhances supply chain performance directly, and partly enhances supply chain performance through SCM capabilities. Further, the effect of SCM capabilities on supply chain performance was very strong and even larger than the effect of IOS use on supply chain performance, revealing the great importance of managing and leveraging SCM capabilities when firms use IOS. 


\section{References}

Agbenyo, L., Asamoah, D., \& Agyei-Owusu, B. (2018). Drivers and Effects of InterOrganizational Systems (IOS) use in a developing country. AMCIS 2018 Proceedings.

Amit, R., \& Schoemaker, P. J. H. (1993). Strategic assets and organizational rent. Strategic Management Journal, 14(1), 33-46.

Asamoah, D., Agyei-Owusu, B., Andoh-Baidoo, F. K., \& Ayaburi, E. (2019). Effect of InterOrganizational Systems Use on Supply Chain Capabilities and Performance. In Y. Dwivedi, E. Ayaburi, R. Boateng, \& J. Effah (Eds.), ICT Unbounded, Social Impact of Bright ICT Adoption (pp. 293-308). Springer International Publishing.

Aydiner, A. S., Tatoglu, E., Bayraktar, E., \& Zaim, S. (2019). Information system capabilities and firm performance: Opening the black box through decision-making performance and business-process performance. International Journal of Information Management, 47, $168-182$.

Bakos, J. Y. (1991). Information Links and Electronic Marketplaces: The Role of Interorganizational Information Systems in Vertical Markets. Journal of Management Information Systems, 8(2), 31-52.

Barki, H., \& Pinsonneault, A. (2005). A Model of Organizational Integration, Implementation Effort, and Performance. Organization Science, 16(2), 165-179.

Barney, J. (1991). Firm Resources and Sustained Competitive Advantage. Journal of Management, 17(1), 99-120.

Bowersox, D. J., Closs, D. J., \& Stank, T. P. (1999). 21st century logistics: Making supply chain integration a reality.

Cepeda, G., \& Vera, D. (2007). Dynamic capabilities and operational capabilities: A knowledge management perspective. Journal of Business Research, 60(5), 426-437.

Chang, H.-L. (2011). Developing supply chain dynamic capability to realise the value of InterOrganisational Systems. International Journal of Internet and Enterprise Management, $7(2), 153-171$.

Chatterjee, D., \& Ravichandran, T. (2004). Inter-organizational information systems research: A critical review and an integrative framework. 37th Annual Hawaii International Conference on System Sciences, 2004. Proceedings of The, 10 pp.-.

Chi, M., Zhao, J., George, J. F., Li, Y., \& Zhai, S. (2017). The influence of inter-firm IT governance strategies on relational performance: The moderation effect of information technology ambidexterity. International Journal of Information Management, 37(2), 4353.

Coates, T. T., \& McDermott, C. M. (2002). An exploratory analysis of new competencies: A resource based view perspective. Journal of Operations Management, 20(5), 435-450.

Cohen, J. (2013). Statistical Power Analysis for the Behavioral Sciences. Routledge.

Danneels, E. (2008). Organizational antecedents of second-order competences. Strategic Management Journal, 29(5), 519-543.

Fornell, C., \& Larcker, D. F. (1981). Structural Equation Models with Unobservable Variables and Measurement Error: Algebra and Statistics. Journal of Marketing Research, 18(3), 382388.

Geisser, S. (1974). A predictive approach to the random effect model. Biometrika, 61(1), 101-107.

Gunasekaran, A., \& Ngai, E. W. T. (2004). Information systems in supply chain integration and management. European Journal of Operational Research, 159(2), 269-295. 
Hair, J. F., Ringle, C. M., \& Sarstedt, M. (2011). PLS-SEM: Indeed a Silver Bullet. Journal of Marketing Theory and Practice, 19(2), 139-152.

Hair, J. F., Risher, J. J., Sarstedt, M., \& Ringle, C. M. (2019). When to use and how to report the results of PLS-SEM. European Business Review, 31(1), 2-24.

Hartono, E., Li, X., Na, K.-S., \& Simpson, J. T. (2010). The role of the quality of shared information in interorganizational systems use. International Journal of Information Management, 30(5), 399-407. h

Helfat, C. E., \& Peteraf, M. A. (2003). The dynamic resource-based view: Capability lifecycles. Strategic Management Journal, 24(10), 997-1010.

Henseler, J., Ringle, C. M., \& Sarstedt, M. (2015). A new criterion for assessing discriminant validity in variance-based structural equation modeling. Journal of the Academy of Marketing Science, 43(1), 115-135.

Kim, K. K., Umanath, N. S., Kim, J. Y., Ahrens, F., \& Kim, B. (2012). Knowledge complementarity and knowledge exchange in supply channel relationships. International Journal of Information Management, 32(1), 35-49.

Koçoğlu, İ., İmamoğlu, S. Z., İnce, H., \& Keskin, H. (2011). The effect of supply chain integration on information sharing:Enhancing the supply chain performance. Procedia - Social and Behavioral Sciences, 24, 1630-1649.

Lee, H., Kim, M. S., \& Kim, K. K. (2014). Interorganizational information systems visibility and supply chain performance. International Journal of Information Management, 34(2), 285295.

Liao, S.-H., \& Kuo, F.-I. (2014). The study of relationships between the collaboration for supply chain, supply chain capabilities and firm performance: A case of the Taiwan's TFT-LCD industry. International Journal of Production Economics, 156, 295-304.

Möller, K., \& Svahn, S. (2006). Role of Knowledge in Value Creation in Business Nets*. Journal of Management Studies, 43(5), 985-1007.

Morash, E. A., \& Lynch, D. F. (2002). Public Policy and Global Supply Chain Capabilities and Performance: A Resource-Based View. Journal of International Marketing, 10(1), 25-51.

Narasimhan, R., \& Kim, S. W. (2001). Information System Utilization Strategy for Supply Chain Integration. Journal of Business Logistics, 22(2), 51-75.

Nitzl, C., Roldan, J. L., \& Cepeda, G. (2016). Mediation analysis in partial least squares path modeling. Industrial Management \& Data Systems, 116(9), 1849-1864.

Peteraf, M. A., \& Barney, J. B. (2003). Unraveling the resource-based tangle. Managerial and Decision Economics, 24(4), 309-323.

Rajaguru, R., \& Matanda, M. J. (2013). Effects of inter-organizational compatibility on supply chain capabilities: Exploring the mediating role of inter-organizational information systems (IOIS) integration. Industrial Marketing Management, 42(4), 620-632.

Ringle, C. M., Wende, S., \& Becker, J.-M. (2015). SmartPLS 3. Www.Smartpls.Com.

Rivard, S., \& Lapointe, L. (2012). Information Technology Implementers' Responses to User Resistance: Nature and Effects. MIS Quarterly, 36(3), 897-920. JSTOR.

Sahin, F., \& Robinson, E. P. (2002). Flow Coordination and Information Sharing in Supply Chains: Review, Implications, and Directions for Future Research. Decision Sciences, 33(4), 505536.

Sezen, B. (2008). Relative effects of design, integration and information sharing on supply chain performance. Supply Chain Management: An International Journal, 13(3), 233-240. 
Shore, B., \& Venkatachalam, A. R. (2003). Evaluating the information sharing capabilities of supply chain partners. International Journal of Physical Distribution \& Logistics Management, 33(9), 804-824.

Stone, M. (1974). Cross-Validatory Choice and Assessment of Statistical Predictions. Journal of the Royal Statistical Society: Series B (Methodological), 36(2), 111-133.

Subramani, M. (2004). How Do Suppliers Benefit from Information Technology Use in Supply Chain Relationships? MIS Quarterly, 28(1), 45-73. JSTOR.

Teece, D. J., Pisano, G., \& Shuen, A. (1997). Dynamic capabilities and strategic management. Strategic Management Journal, 18(7), 509-533.

Voorhees, C. M., Brady, M. K., Calantone, R., \& Ramirez, E. (2016). Discriminant validity testing in marketing: An analysis, causes for concern, and proposed remedies. Journal of the Academy of Marketing Science, 44(1), 119-134.

Wang, E. T. G., Tai, J. C. F., \& Wei, H.-L. (2006). A Virtual Integration Theory of Improved Supply-Chain Performance. Journal of Management Information Systems, 23(2), 41-64.

Wang, E. T. G., \& Wei, H.-L. (2007). Interorganizational Governance Value Creation: Coordinating for Information Visibility and Flexibility in Supply Chains*. Decision Sciences, 38(4), 647-674.

Williamson, E. A., Harrison, D. K., \& Jordan, M. (2004). Information systems development within supply chain management. International Journal of Information Management, 24(5), 375385.

Won Lee, C., Kwon, I. G., \& Severance, D. (2007). Relationship between supply chain performance and degree of linkage among supplier, internal integration, and customer. Supply Chain Management: An International Journal, 12(6), 444-452.

Wu, F., Yeniyurt, S., Kim, D., \& Cavusgil, S. T. (2006). The impact of information technology on supply chain capabilities and firm performance: A resource-based view. Industrial Marketing Management, 35(4), 493-504.

Yu, W., Chavez, R., Jacobs, M. A., \& Feng, M. (2018). Data-driven supply chain capabilities and performance: A resource-based view. Transportation Research Part E: Logistics and Transportation Review, 114, 371-385.

Zhang, Q., \& Cao, M. (2018). Exploring antecedents of supply chain collaboration: Effects of culture and interorganizational system appropriation. International Journal of Production Economics, 195, 146-157. 


\section{Appendix: Measurement scales of constructs}

\section{IOS Use for Communication}

APCOM1: Our firm and supply chain partners use IOS for workflow coordination APCOM2: Our firm and supply chain partners use IOS for conferencing APCOM3: Our firm and supply chain partners use IOS for message services (dropped) APCOM4: Our firm and supply chain partners use IOS for frequent contacts APCOM5: Our firm and supply chain partners use IOS for multiple channel communication

\section{IOS Use for Intelligence}

APINTL1: Our firm and supply chain partners use IOS for understanding trends in sales and customer preferences

APINTL2: Our firm and supply chain partners use IOS for storing, searching, and retrieving business information

APINTL3: Our firm and supply chain partners use IOS for deriving inferences from past events (e.g., process exceptions, patterns of demand shifts, what worked and what did not work)

APINTL4: Our firm and supply chain partners use IOS for combining information from different sources to uncover trends and patterns (dropped)

APINTL5: Our firm and supply chain partners use IOS for interpreting information from different sources in multiple ways depending upon various requirements (dropped)

\section{Supply Chain Information Exchange Capability}

SCINFX1: Our firm exchanges more information with our supply chain partners

SCINFX2: Our firm benefits more from information exchange with our supply chain partners

SCINFX3: Information flows more freely between our firm and supply chain partners

SCINFX4: Information exchange with our supply chain partners is accurate and timely

\section{Supply Chain Coordination Capability}

SCCOD1: Our firm is more efficient in coordination activities with our supply chain partners (dropped)

SCCOD2: Our firm conducts transaction follow-up activities more efficiently with our supply chain partners

SCCOD3: Our firm spends less time coordinating transactions with our supply chain partners than our competitors

SCCOD4: Our firm has reduced coordinating costs more than our competitors

SCCOD5: Our firm can conduct the coordination activities at less cost than our competitors

\section{Supply Chain Integration Capability}

SCINTG1: Our firm develops strategic plans in collaboration with our supply chain partners

SCINTG2: Our firm collaborates actively in forecasting and planning with our supply chain partners

SCINTG3: Our firm projects and plans future demand collaboratively with our supply chain partners

SCINTG4: Our firm always forecasts and plans activities collaboratively with our supply chain partners 


\section{Supply Chain Responsiveness Capability}

SCRESP1: Our firm and supply chain partners understand trends in sales and customer preferences SCRESP2: Our firm and supply chain partners promote storing, searching, and retrieving business information (share common database)

SCRESP3: Our firm and supply chain partners derive inferences from past events (e.g., process expectations, patterns of demand shifts, what worked and what did not work)

SCRESP4: Our firm and supply chain partners use information from different partners in multiple ways depending upon various requirements

\section{Reliability Performance}

SPREL1: Our firm with supply chain partners offers products that are highly reliable

SPREL2: Our firm with supply chain partners offers high quality products to our customers

SPREL3: Our firm and supply chain partners have helped each other to improve product quality

SPREL4: Our firm with supply chain partners increases the rate at which we fulfill customer orders SPREL5: Our firm with supply chain partners increases our inventory turns

\section{Efficiency Performance}

SPEFF1: Our firm with supply chain partners reduces inbound and outbound cost of transport SPEFF2: Our firm with supply chain partners reduces warehousing and inventory holding costs SPEFF3: Our firm with supply chain partners meets on-time delivery requirements for all product SPEFF4: Our firm with supply chain partners reach agreed costs per unit as compared with industry

\section{Flexibility Performance}

SPFLX1: Our firm with supply chain partners offers a variety of products and services efficiently SPFLX2: Our firm with supply chain partners offers customized products and services with different features

SPFLX3: Our firm with supply chain partners meets different customer volume requirements efficiently

SPFLX4: Our firm with supply chain partners has short customer response time as comparison to industry

SPFLX5: Our firm with supply chain partners responds to and accommodates demand variations 